\title{
Antioxidant activity and in-vitro Potential inhibition of Nigella sativa and Saussurea lappa against LDL oxidation among Sundance
}

\author{
Isam Sadik ${ }^{1^{\star}}$, Alawiya Abd Allah ${ }^{2}$, Mohammed Abdulhameed ${ }^{3}$, Mashair Abdelkader $^{4}$, Nazra \\ Sayed ${ }^{5}$, Anhar Nour ${ }^{6}$, Abid Algadir Tom ${ }^{7}$ \\ ${ }^{1,2,6}$ Department of Clinical Chemistry, Faculty of Laboratory Science, Omdurman Islamic University \\ ${ }^{3}$ Department of Pathology, Faculty of Medicine, Omdurman Islamic University \\ ${ }^{4}$ Department of Pediatric, Faculty of Medicine, Neelain University \\ ${ }^{5}$ Ministry of Health, Turkey \\ ${ }^{7}$ Department of Clinical Chemistry ,University of Tigana
}

Accepted April 23, 2017

\begin{abstract}
It's well documented that oxidized low density lipoprotein (LDL) plays a major role in the modification of atherosclerosis. Nigella sativa (NS) and Saussurea lappa (SL) in literature documented as a good antioxidant.To undertaken to evaluate the ability of NS and SL for inhibition of LDL oxidation in-vitro, in fact Nigella sativa and Saussurea lappa LDL was collected by ultracentrifugation and enhanced to oxidize by $\mathrm{CuSO}_{4}$ and $\mathrm{NS}$ and $\mathrm{SL}$ were used to inhibit LDL oxidation in-vitro. Free radical scavenging of $50 \%$ of radicals of DPPH and phenolic content of both herbals were measured to assess the antioxidant activity and compared with standard antioxidant (vitamin E). The inhibitory effect of NS, SL and vitamin E against oxidation ratio was significantly better than in non addition of both herbals $(p<0.01)$; NS was better than $S L(p<0.01)$; and comparable with vitamin E. Both herbals possess good antioxidant activity against DPPH radicals and have high phenolic contents enable it to inhibit LDL oxidation in-vitro. NS and SL possess strong antioxidant activity comparable with vitamin $E$ and good for cardiovascular health.
\end{abstract}

Keywords: Nigella sativa, Saussurea lappa, vitamin E, LDL oxidation, antioxidant activity.

Introduction

The adverse effects of oxidative stress on human health have become a serious issue. Oxidative modification of low-density lipoprotein (LDL) was shown to play a key role in the initiation of atherogenesis. Oxidative modification of LDL greatly increases its atherogenicity and is considered to be a key step in the development of atherosclerosis (Steinberg et al., 1989) The susceptibility of LDL to oxidation in vitro has been reported to be associated with the severity of atherosclerosis (Regnstrom et al., 1992).

${ }^{*}$ Corresponding Author Email:isnaalah@yahoo.com
Also, auto antibodies against oxidized LDL seem to predict the progression of carotid atherosclerosis (Salonen et al., 1992) .Nigella sativa (NS) commonly named as black seed or black cumin. Traditionally, it has been in use in many Middle Eastern countries as a natural remedy for DM, and significant reduction in blood glucose level in humans following the use of the plant. NS has a hypoglycemic effect, can occur whether it is used as oil ( El-Shamy et al., 2000). powder or even in a plant mixture( El-Shabrawy et al., 1996, and Ohmori et al., 2005). Saussurea lappa (SL), belonging to the family of Asteraceae and one of the best-known species within its genus, is a perennial, aromatic, and medicinal plant has been used in folk medicine for the treatment of various ailments and diseases such as viz., asthma, 
certain bronchitis, ulcer, and stomach problems since ancient times (Pandy et al ., 2007). Saussurea lappa showed the strongest inhibitory potential on 2,2-diphenyl1-picrylhydrazyl (DPPH) radicals, Saussurea lappa can be used as an alternative antioxidant agent in the medical and food industry Chang. et al .,2012). Many studies done in about the antioxidant activities of NS and SL (specially NS), but no one use both herbals to inhibit of LDL oxidation with, so this work undertaken to evaluate the ability of NS and SL for inhibition of LDL oxidation invitro, in fact Nigella sativa and Saussurea lappa has occupied a special place in Islamic civilization.

\section{Subjects and methods}

\section{Subjects}

One hundred thirty one hyperlipidemic patients randomly selected from different hospitals in Khartoum estate (suba teaching hospital, Omdurman teaching hospital, and Khartoum north teaching hospital.) During June 2014 to July 2015, baseline serum total cholesterol and LDL-C concentrations were (mean $\pm S D)(5.60 \pm 0.15$ and $4.00 \pm 0.13 \mathrm{mmol} / \mathrm{L}$ ) respectively.

\section{Methods}

\section{Plant materials}

$N S$ and $S L$ purchased from local market, and then it dried in open air environment in direct sun light for 3 days, followed by grinding to get powder. $300 \mathrm{~g}$ dry weight powder extracted twice with $1000 \mathrm{~mL}$ absolute methanol using ultrataurix. The solvent distilled off under reduced pressure using a Buchi rotary evaporator and the dried methanolic extracts kept at $4^{\circ} \mathrm{C}$ till biological tests.

\section{Sample preparation}

The method as described by (McDowell et al ., 1995).LDL ultra-centrifugation:Plasma separated from heparinized blood by centrifugation at $2000 \mathrm{rpm}$ for $10 \mathrm{~min}$. LDL isolated by a density gradient method using a Beckman TLI00 ultracentrifuge (Beckman Instruments, Glenrothes, UK), with a fixed angle rotor (100' 3) and 'Quickseal' $3 \mathrm{~mL}$ polyallomer tubes. Plasma $\left(0^{\prime} 9 \mathrm{~mL}\right)$ then added to a centrifuge tube containing potassium bromide $(0,4451 \mathrm{~g}$; Sigma Chemicals, Poole, UK), using a pipette tips to a tube and gently mixed until the salt dissolved and adjusting the density of plasma to $1.30 \mathrm{~kg} / \mathrm{L}$. This was then overlaid with $2.1 \mathrm{~mL}$ of $0.15 \mathrm{~mol} / \mathrm{L} \mathrm{NaCl}$ (density = $1.006 \mathrm{~kg} / \mathrm{L}$ ) and centrifuged at $100000 \mathrm{rpm}$ for $60 \mathrm{~min}$. This creates a density gradient such that LDL forms a discrete orange colored band approximately one-third from the top of the tube. LDL was removed into a volume of approximately $0.9 \mathrm{~mL}$ by puncturing the side wall of the tube with a 21 gauge hypodermic needle; first allow air to enter by a second needle in the top of the tube.

\section{LDL oxidation}

Oxidation promote by the addition of copper sulphate (50 $\mu \mathrm{L}$ of $40 \mu \mathrm{mol} / \mathrm{L}$ stock Analar grade $\mathrm{CuSO}_{4}$ ) to give a final concentration of $2 \mu \mathrm{mol} / \mathrm{L}$. The cuvettes were placed in an automatic six cell changer which was accurately thermostatted to $37^{\circ} \mathrm{C}$. Absorbance readings at $234 \mathrm{~nm}$ were taken every 2 minutes by a Hitachi U2000 spectrophotometer. The following parameters recorded: Lag time: calculated as the time intercept between the line of maximum slope of the propagation phase and the absorbance baseline at time. Total absorbance change. Slope of initial phase. Slope of propagation phase.

\section{Free radical-scavenging activity}

The method described by (Ohmori et al., 2005). The -free radical-scavenging activity determine using 1,1-diphenyl2-picrylhydrazyl (DPPH) (Wako Pure Chemical Industries. Osaka. Japan). The volume of both plants required to cause a $50 \%$ decrease in the absorbance at $516 \mathrm{~nm}$ relative to control then calculated, and free radical-scavenging activity calculated as inhibition using the following equation: DPPH radical scavenging activity $(\%)=1-[A s / A c] \times 100 . A_{s}$ : absorbance of the DPPH solution containing samples. $A_{c}$ : absorbance of the control solution without sample but with DPPH ( Leong, et al., 2002). The percentages of DPPH reduced were plotted against the samples. The experiment was also carried out using vitamin $\mathrm{E}\left(0.1 \mathrm{mg} \mathrm{mL}^{-1}\right)$ as standard antioxidant. The samples were analyzed in triplicates then mean and standard deviation (SD) (mean $\pm S D)$ was calculated.

\section{Determination of total phenolic content}

The method described by ( Singleton et al.,1999). With Folin-Ciocalteu reagent (FCR) using spectrophotometer for quantification. Briefly, $125 \mu$ l of FCR (10\%) and $125 \mu \mathrm{l}$ of sample were mixed with each other and incubated for $6 \mathrm{~min}$, and then $125 \mu \mathrm{l}$ of $7 \% \mathrm{Na}_{2} \mathrm{CO}_{3}$ for $30 \mathrm{~min}$. The phenolic compounds and phosphomolybdic acid were reacted and produce a blue-colored complex its absorbance recorded spectrophotometrically with wavelength $760 \mathrm{~nm}$. With standard calibration curve using gallic acid as standard, total phenolic contents was explained as Gallic Acid Equivalents (GAE) mg/g dry weight (DW). 
Table 1: antioxidant activity of NS and SL against DPPH radical's $\mu \mathrm{g} / \mathrm{ml}$, oxidation ratio and total phenol contents of NS, SL and Vitamin E in patients

\begin{tabular}{lccc}
\hline & DPPH test $\boldsymbol{\mu g} / \mathbf{m l}$ & Oxidation ratio $(\mathbf{n m o l} / \mathbf{m i n} / \mathbf{m g}$ LDL protein) & Total phenol (mg GAE/g DW) \\
\hline Control & - & $11.6 \pm 1.3$ & - \\
NS & $6.2 \pm 1.2^{*}$ & $3.0 \pm 1.2^{*} \#$ & $19.9 \pm 4.8^{*}$ \\
SL & $9.7 \pm 1.6$ & $4.7 \pm 1.2^{*}$ & $16.8 \pm 2.4$ \\
Vitamin E & $5.6 \pm 1.4^{*} \#$ & $2.8 \pm 1.1^{*} \#$ & $22.0 \pm 5.2^{*} \#$ \\
\hline
\end{tabular}

* Significant compared to SL level $(p<0.01)$. \# Significant compared to NS level $(p<0.01)$. Control: with addition of $\mathrm{CuSO}_{4}$ and without addition of herbals.

Table 2: Lag time (min) of NS, SL and Vitamin E

\begin{tabular}{|c|c|}
\hline & Lag time (min) \\
\hline Control & $25.3 \pm 3.2 \quad(1.0)$ \\
\hline NS & $208.3 \pm 26.7 \quad(8.4)^{\star} \#$ \\
\hline SL & $178.7 \pm 12.8 \quad(7.1)^{*}$ \\
\hline Vitamin E & $215.4 \pm 23.2 \quad(8.6)^{\star} \# \$$ \\
\hline
\end{tabular}

* Significant compared to control level $(p<0.01)$. \# Significant compared to SL level $(p<0.01)$. \$ Significant compared to NS level $(p<0.05)$.

\section{Statistical analysis}

SPSS software (version 16) was used for analysis of variables. Descriptive statistics used to analyze all variable studies Data were summarizing as mean \pm SD. Variables were compare between study group and control group by Student's t test method, $p$ value of $<$ 0.05 was considered significant.

\section{Ethical approval}

This study was performed after approval ethical committee of Omdurman Islamic University and Ministry of Health in Khartoum Sudan.

\section{RESULTS}

The antioxidant activity of NS, SL and vitamin E antioxidant concerning scavenging of $50 \%$ of the radicals of DPPH (Inhibitory Concentration $\mathrm{IC}_{50}$ ) was delivered in table 1 . For scavenging of $50 \%$ of the radicals of DPPH (Inhibitory Concentration $\mathrm{IC}_{50}$ ), 6.2 $2 \pm 1.2,9.7 \pm 1.6,5.6 \pm 1.4$ $\mu \mathrm{g} / \mathrm{ml}$ of NS, SL and vitamin E respectively was required. The mean level of oxidation ratio of NS, SL and Vitamin $E$, the inhibitory effect against rate of oxidation of NS, SL and vitamin $E$ was significantly better than the effect of control $(p<0.01)$. The inhibitory effect against rate of oxidation of NS was significantly better than the effect of $\mathrm{SL}$ and comparable with vitamin $\mathrm{E}$ level $(3.0 \pm 1.2 \mathrm{Vs}$ $4.7 \pm 1.2 \mathrm{nmol} / \mathrm{min} / \mathrm{mg}$ LDL protein respectively) $(p<0.01)$, whereas the inhibitory effect against rate of oxidation of vitamin $\mathrm{E}(2.8 \pm 1.1 \mathrm{nmol} / \mathrm{min} / \mathrm{mg} \mathrm{LDL}$ protein). The mean $\pm S D$ of oxidation ratio of NS, SL and Vitamin $E$ in patients according to hyperlipidemia types (mild, moderate and severe hyperlipidemia), $(p<0.01)$. Table 1 revealed the total phenol contents of NS, SL vitamin E, phenolic content of NS and vitamin was better than that of SL $(19.9 \pm 4.8,22.2 \pm 5.2$ vs $16.8 \pm 2.4 \mathrm{mg} \mathrm{GAE} / \mathrm{g}$ DW respectively), whereas vitamin $E$ phenolic contents was better than that of NS significantly $(p<0.01)$. Table 2 shows the lag time value (min) of control, NS, SL and Vitamin E. The lag time of NS, SL and Vitamin E was significantly higher than that of control (208.3 \pm 26.7 , $178.7 \pm 12.8$ and $215.4 \pm 23.2$ vs. $25.3 \pm 3.2$ min respectively) $(p<0.01)$. NS, SL and Vitamin $E$ time was higher than control by $(8.4,7.1$ and 8.6 times respectively).

\section{DISCUSSION}

There were many studies show that LDL oxidation can be inhibited by an appropriate antioxidants; many natural antioxidants and herbal medicine was used to inhibit this oxidation. ( Sánchez-Moreno et al .,2002)for example Ohmori et al., 2005), use green tea, ( Thounaojam et al .,2011). use Sida rhomboidea, (Gajaria et al., 2015 and Ahmed et al., 2015) use two mint types. Our study we use NS and SL was used for inhibition of LDL oxidation in vitro, the antioxidant activity of both herbals was determined with the ability to remove free radical DPPH and with the ability to remove the reactive oxygen species (superoxide anion O2-), the EO of both herbals possess high ability to inhibit the free radical of $\mathrm{DPPH}$, this finding agreed with (Hajlaoui et al.,2009 and Ahmed et al., 2015). Vitamin $E$ posses strong inhibitory effect compared to both herbals $(P<0.01)$; in the way NS was better than $S L$ for inhibit free radical of DPPH $(P<0.01)$. Inhibitory effect of NS and SL against LDL oxidation ratio 
mediated by CuSO4 compared with control and vitamin $\mathrm{E}$ explained that both NS and SL was significantly higher effective than control $(P<0.01)$, also NS was higher effective than $S L$ against oxidation rate $(P<0.01)$, but NS was comparable effectively with vitamin $E$ (not statistically significant) (3.0 for NS, 4.7 for SL, 2.8 for vitamin $\mathrm{E}$ and 11.6 for control with addition of $\mathrm{CuSO}_{4}$ and without addition of any herbal $\mathrm{nmol} / \mathrm{min} / \mathrm{mg} \mathrm{LDL}$ protein. From this point we can say NS possess a good antioxidant comparable with standard antioxidant (vitamin E) in agree with (Mehta et al. ,2008).

The antioxidant activity of our both herbals attributed for total phenolic content, this justify and support the behavior of both herbals for stopping LDL oxidation specially NS, NS phenolic content was found in this study higher than $S L(p<0.01)$, while vitamin $E$ possess high phenolic content than both NS and SL $(p<0.01)$. The higher phenolic contents of NS was agreed with ( Mariod.,2009 and Goga et al.,2012).With different level of phenolic content and antioxidant activity in both studies but comparable with our finding, and higher phenolic contents of SL was agreed with (Chang et al., 2012).The prolongation of the lag phase in the presence of vitamin E, NS and SL indicating their antioxidant effect to reduce the role of $\mathrm{CuSO} 4$ to enhancement LDL oxidation. NS was the most effective in lag time prolongation than control ( 8.4 folds than control, significant $p<0.01$ ), while the SL was better in increase the lag time than control with 7.1 folds, significant $p<0.01$. NS significant increase the lag time more than SL (significant $p<0.01$ ). Vitamin $\mathrm{E}$ was better than both control and SL in the prolongation of the lag time (significant $p<0.01$ ), and better than NS (significant $p<0.05)$. The phenol varied $(19.9,16.8 \mathrm{mg}$ GAE/g DW) for NS and SL respectively, which it's a great amount comparable with the vitamin $\mathrm{E}(22.2 \mathrm{mg} \mathrm{GAE} / \mathrm{g}$ DW), greater amount of phenolic component lead to more potent radical scavenging by using stable 2,2-diphenyl-1picrylhydrazyl (DPPH) radical scavenging effect of the extract was determined spectra photo metrically, different concentration of each herbal extract were added at an equal volume to methanolic solution of DPPH after fifteen minutes at room temperature the absorbance was recorded at 517nano-meter $(\mathrm{nm})$. The experiment was repeated three times, vitamin $E$ used as standard control. ( Rice-Evans et al., 1996) said that the antioxidant activity of herbal materials attributed to its total phenolic and flavonoid content, our study agreed with this finding. The different between antioxidant activities between (NS and SL) in our study and other studies in different areas are suggested may be for different herbal constituents, constituents amounts, plant grow soil, environment, use of fertilizer and pesticides. In Saudi Arabia there are many studies reporting the prevalence of hyperlipidemia which reach a medical problems, ( Al-Nuaim et al., 1996; Al-Nuaim et al.,1997, and Al-Nozha et al.,2008) and ( AlKaabba et al.,2012). There is an urgent need for a plan targeting to identify the causes for gain more attention and proper management.

\section{Conclusion}

NS and SL possess strong antioxidant activity attributed to its high phenolic contents, the antioxidant activity of NS was comparable with standard antioxidant (vitamin E) enable it to be good for atherosclerosis prevention and cardiovascular health.

\section{References}

Ahmed AM, Ozbak HA, Hemeg HA( 2015). Effect of essential oil of traditional two Saudi mint types and its possible role in cardiovascular and throat health. Int J Clin Exp Med; 8(5):8060-8068.

Al-Kaabba AF, Al-Hamdan NA, El Tahir A, Abdalla AM, Saeed AA, Hamza MA (2012).Prevalence and Correlates of Dyslipidemia among Adults in Saudi Arabia: Results from a National Survey. Open Journal of Endocrine and Metabolic Diseases; 2: 89-97.

Al-Nozha MM, Arafah MR, Al-Maatouq MA, Khalil MZ, Khan NB, AlMarzouki K, Al-Mazrou YY, Abdullah M, Al-Khadra A, Al-Harthi SS, Al-Shahid MS, Al-Mobeireek A, Nouh MS. (2008) Hyperlipidemia in Saudi Arabia. Saudi Med J; 29: 282-7.

Al-Nuaim AR, Al-Rubeaan K, Al-Mazrou Y, Al-Attas O, (1996) AlDaghari N. Prevalence of hypercholesterolemia in Saudi Arabia, epidemiological study. Int J Cardiol; 54: 41-49.

Al-Nuaim AR ( 1997). Serum total and fractionated cholesterol distribution and prevalence of hypercholesterolemia in urban and rural communities in Saudi Arabia. Int J Cardiol; 58:141-9.

Chang KM, Choi SI, Kim GH (2012). Anti-oxidant Activity of Saussurea lappa C.B. Clarke Roots. Prev Nutr Food Sci; 17(4): 306-309.

Chang KM, Choi SI, Kim GH.( 2012). Anti-oxidant Activity of Saussurea lappa C.B. Clarke Roots. Prev Nutr Food Sci; 17(4): 306-309.

El-Shabrawy OA, Nada SA( 1996).Biological evaluation of multicomponent tea used as hypoglycemic in rats. Fitoterapia.; 67(2): 99-102.

El-Shamy KA, Abdel Ghafaar N, Hanna RA, Girgis RB, Yaramian MA, Adeeb NA( 2000). Liver and serum vitamins $A, E$ and B-carotene in NIDDM rats treated with antihyperglycemic plants. Med. J. Cairo Univ; 68(4): 147-157.

Gajaria TK, Patel DK, Devkar RV, Ramachandran AV( 2015). Flavonoid rich extract of Murraya Koenigii alleviates in-vitro LDL oxidation and oxidized LDL induced apoptosis in raw 264.7 Murine macrophage cells. J Food Sci Technol; 52: 3367-75.

Goga A, Hasić S, Bećirović, Ćavar, S. Phenolic (2012).Compounds and Antioxidant Activity of Extracts of $\mathrm{N}$ i g e I I a s a t i va L. Bulletin of the Chemists and Technologists of Bosnia and Herzegovina.:39; 1520.

Hajlaoui $H$, Trabelsi N, Noumi E, Snoussi M, Fallah H, Ksouri R, Bakhrouf A( 2009). Biological activities of the essential oils and methanol extractof tow cultivated mint species (Mentha longifolia and Mentha pulegium) used in the Tunisian folkloric medicine. World $\mathrm{J}$ Microbiol Biotechnol; 25: 2227-2238.

Leong, LP. \& Shui, G. ( 2002). An Investigation of Antioxidant Capacity of Fruits in Singapore Markets. Food Chemistry; 76:69-75.

Mariod AA, Ibrahim RM, Ismail M, Ismail N (2009). Antioxidant activity and phenolic content of phenolic rich fractions obtained from black cumin (Nigella sativa) seedcake. Food Chemistry.:116; 306-312.

McDowell IF, McEneny J, Trimble ER.( 1995). A rapid method for measurement of the susceptibility to oxidation of low-density lipoprotein. Am Clin Biochem; 32:167-74

Mehta BK, Verma M, Gupta M ( 2008). Novel lipid constituents identified in seeds of Nigella sativa (Linn). J. BrazChem. Soc. ; 19(3). 
Ohmori R, Iwamoto T, Tago M, Takeo T, Unno T, Itakura H, Kondo K. (. 2005).Antioxidant Activity of Various Teas Against Free Radicals and LDL Oxidation. Lipids; 40(8): 849-53.

Pandy MM, Rastogi S, Rawat AKM( 2007). Saussurea costus: Botanical, chemical and pharmacological review of ayuvedic medicinal plant. J Ethnopharmacol.; 110: 379-390.

Regnstrom J, Nilsson J, Tornvall P, Landou C, Hamsten A (1992). Susceptibility to low-density lipoprotein oxidation and coronary atherosclerosis in man. Lancet. 339: 1183-1186.

Rice-Evans CA, Miller JM, Paganga G(1996).Structure-antioxidant activity relationship of flavonoids and phenolic acids. Free Radic Biol Med; 20: 933-956.

Salonen K, Nyyssonen W, Palinski JL (1992). Witztum. Autoantibody against oxidized LDL and progression of carotid atherosclerosis. Lancet; 339: 883-887.

Sánchez-Moreno C ( 2002): Methods Used to Evaluate the Free Radical Scavenging Activity in Foods and Biological Systems. Food Sci Technol Int; 8: 121-137.
Singleton VL, Orthofer R, Lamuela-Raventos RM( 1999). Analysis of total phenols and other oxidation substrates and antioxidants by means of Folin- Ciocalteu reagent. Methods Enzymol; 299: 152-178.

Steinberg D, Parthasarathy S, Carew TE, Khoo JC, Witztum JL.( 1989) Beyond cholesterol. Modifications of low-density lipoprotein that increase its atherogenicity. N Engl J Med; 320: 915-24.

Thounaojam MC, Jadeja RN, Devkar RV, Ramachandran AV ( 2011). In vitro evidence for the protective role of Sidarhomboidea. Roxb extract against LDL oxidation and oxidized LDL-induced apoptosis in human monocyte-derived macrophages. Cardiovasc Toxicol; 11: 168-79. 